\title{
A Unified Catalog of Earthquake Hypocenters and Magnitudes at Volcanoes in Alaska—1989 to 2018
}

Scientific Investigations Report 2019-5037

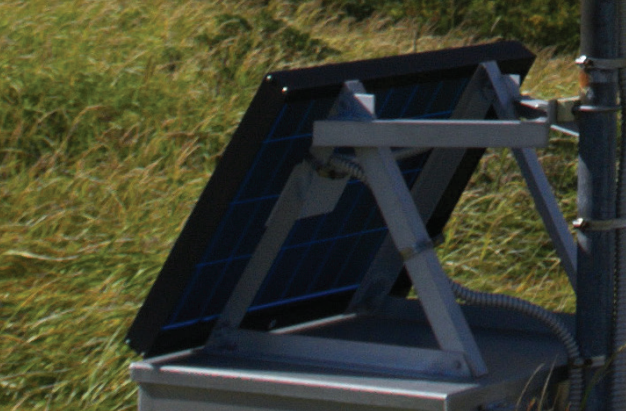

U.S. Department of the Interior

U.S. Geological Survey

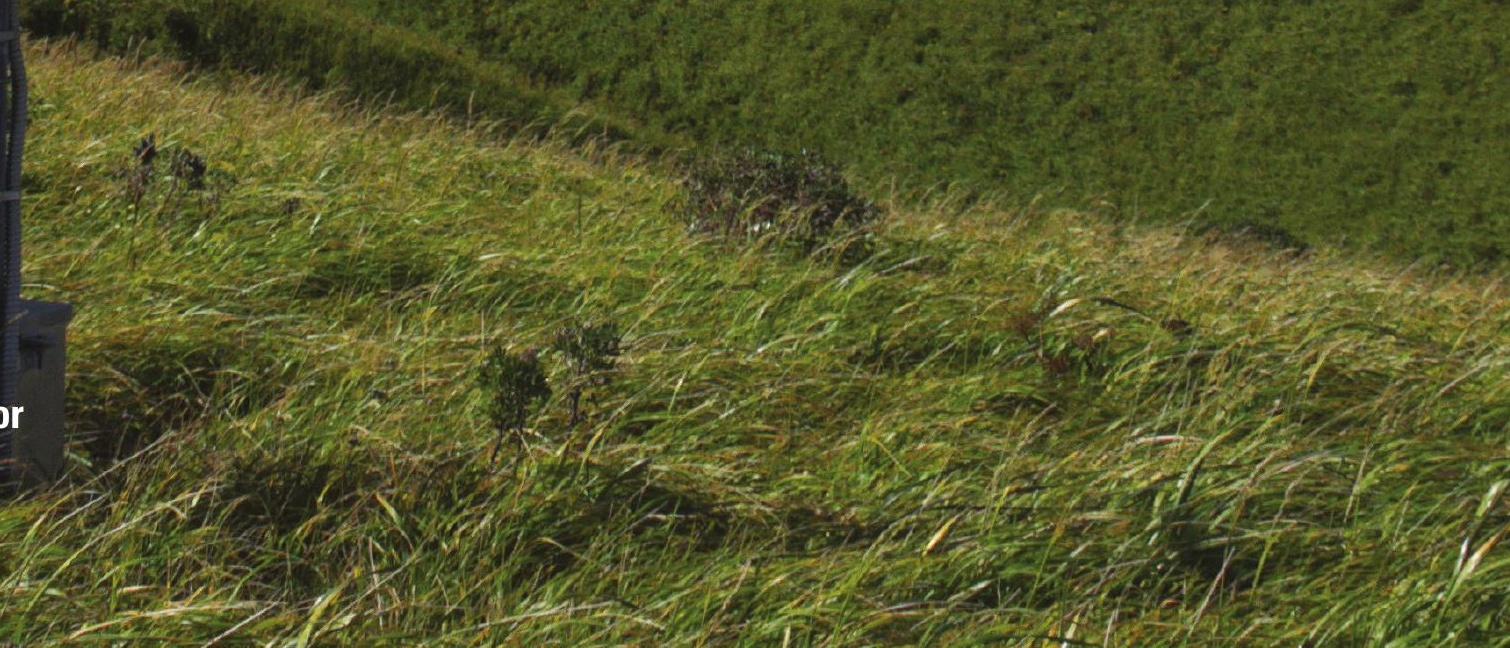


COVER . Seismic station KINC located on the east side of Kanaga Volcano in the western Aleutian Volcanic Arc (U.S. Geological Survey photograph by John Lyons). 


\section{A Unified Catalog of Earthquake Hypocenters and Magnitudes at Volcanoes in Alaska-1989 to 2018}

By John A. Power, Paul A. Friberg, Mathew M. Haney, Thomas Parker, Scott D. Stihler, and James P. Dixon

Scientific Investigations Report 2019-5037 


\title{
U.S. Department of the Interior \\ DAVID BERNHARDT, Secretary
}

\author{
U.S. Geological Survey \\ James F. Reilly II, Director
}

U.S. Geological Survey, Reston, Virginia: 2019

For more information on the USGS - the Federal source for science about the Earth, its natural and living resources, natural hazards, and the environment-visit https://www.usgs.gov or call 1-888-ASK-USGS.

For an overview of USGS information products, including maps, imagery, and publications,

visit https://store.usgs.gov.

Any use of trade, firm, or product names is for descriptive purposes only and does not imply endorsement by the U.S. Government.

Although this information product, for the most part, is in the public domain, it also may contain copyrighted materials as noted in the text. Permission to reproduce copyrighted items must be secured from the copyright owner.

Suggested citation:

Power, J.A., Friberg, P.A., Haney, M.M., Parker, T., Stihler, S.D., and Dixon, J.P., 2019, A unified catalog of earthquake hypocenters and magnitudes at volcanoes in Alaska-1989 to 2018: U.S. Geological Survey Scientific Investigations Report 2019-5037, 17 p., https://doi.org/10.3133/sir20195037.

ISSN 2328-0328 (online) 


\section{Acknowledgments}

We thank John Lahr (former USGS) and Fred Klein (USGS) for their long-term contributions to locating earthquakes at volcanoes. Formal reviews by Aaron Wech (USGS), Diana Roman (Carnegie Institution for Science), and Jeremy Pesicek (USGS) improved the text and figures. 


\section{Contents}

Acknowledgments ........................................................................................................................

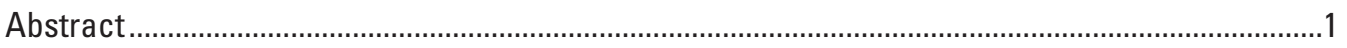

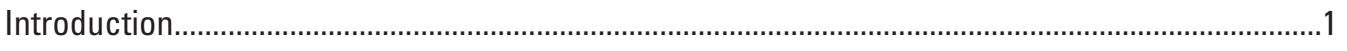

Earthquake Catalog —Instrumentation, Data Acquisition, and Processing ......................................

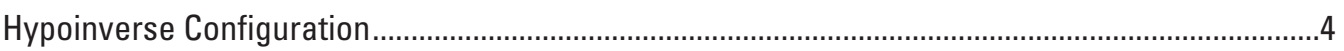

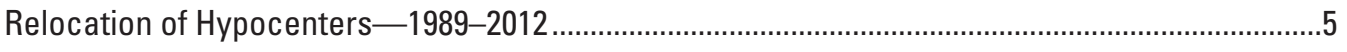

Comparison of Hypoellipse and Hypoinverse Hypocenters ……...........................................

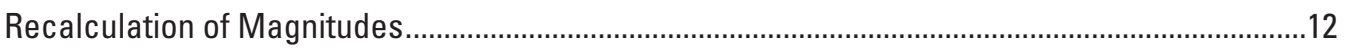

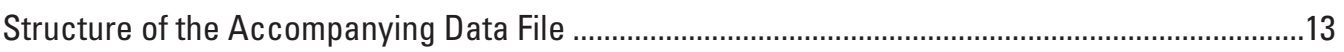

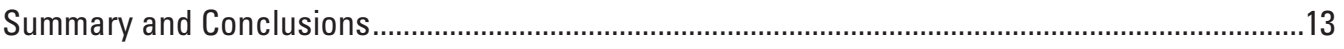

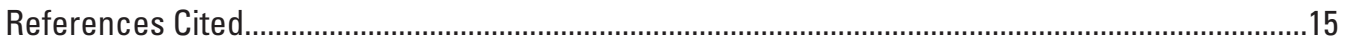

Appendix-TAR File for the Alaska Volcano Observatory Unified Earthquake

Catalog - 1989-2018......................................................................................................

\section{Figures}

1. Map of volcanoes seismically monitored by the Alaska Volcano Observatory ................2

2. Map of permanent seismic stations operated in Alaska ...................................................

3. Graph showing number of earthquakes located by the Alaska Volcano Observatory (AVO) each month from October 1989 through December 2017

4. Simplified map and east-west cross-section showing hypocenters at Redoubt Volcano, Alaska, during December 1989.

5. Simplified map and east-west cross-section showing hypocenters at Akutan Peak volcano, Alaska, between January 1, 2000, and January 1, 2011

6. Simplified map and east-west cross-section showing hypocenters at Tanaga Volcano, Alaska, between January 1, 2000, and January 1, 2011

7. Simplified map and east-west cross-section showing hypocenters at Okmok Caldera, Alaska, between January 1, 2000, and January 1, 2011

8. Graphs showing calculated changes in the position of earthquakes located by the Alaska Volcano Observatory between October 1989 and February 1, 2012

9. Graphs showing changes in calculated magnitude by year for earthquakes located by the Alaska Volcano Observatory (AVO) from February 1, 2012, through 


\section{Tables}

1. Seismic stations in Alaska with unknown response information (see Dixon and others,

2013, for station locations).

2. Stations with noncompliant component names and the new name used in the Advanced National Seismic System (ANSS) Quake Monitoring System (AOMS) (see Dixon and others, 2013, for station locations).

\section{Conversion Factors}

International System of Units to U.S. customary units

\begin{tabular}{lll}
\hline Multiply & By & To obtain \\
\hline & Length & \\
\hline kilometer $(\mathrm{km})$ & 0.6214 & mile $(\mathrm{mi})$ \\
\hline
\end{tabular}

\section{Datum}

Horizontal coordinate information is referenced to the World Geodetic System 1984 (WGS 84).

\section{Abbreviations}

$\begin{array}{ll}\text { A1VCO } & \text { A1 voltage control oscillator } \\ \text { AEC } & \text { Alaska Earthquake Center } \\ \text { ANSS } & \text { Advanced National Seismic System } \\ \text { AQMS } & \text { ANSS Quake Monitoring System } \\ \text { AtoD } & \text { analog to digital } \\ \text { AVO } & \text { Alaska Volcano Observatory } \\ \text { Hz } & \text { hertz } \\ \text { IASPEI } & \text { International Association of Physics of the Earth's Interior } \\ \text { IRIS DMC } & \text { Incorporated Research Institutions for Seismology Data Management Center } \\ \text { NEIC } & \text { National Earthquake Information Center } \\ \text { SEED } & \text { Standard for the Exchange of Earthquake Data } \\ \text { SVD } & \text { singular-value decomposition } \\ \text { USGS } & \text { U.S. Geological Survey } \\ \text { Y2K } & \text { year 2000 computer bug }\end{array}$





\title{
A Unified Catalog of Earthquake Hypocenters and Magnitudes at Volcanoes in Alaska-1989 to 2018
}

\author{
By John A. Power, ${ }^{1}$ Paul A. Friberg, ${ }^{2}$ Mathew M. Haney, ${ }^{1}$ Thomas Parker, ${ }^{1}$ \\ Scott D. Stihler, ${ }^{3}$ and James P. Dixon ${ }^{1}$
}

\section{Abstract}

The Alaska Volcano Observatory (AVO) has maintained an earthquake catalog since 1989 that now contains over 120,000 hypocenters and magnitudes that occurred near Alaskan volcanoes. Since 1989 the seismic instrumentation and data acquisition and processing techniques have undergone numerous changes as computer systems and seismic processing software have advanced and evolved. In this report we recalculate earthquake hypocenters and magnitudes in a consistent manner between October 1989 and January 2018. The new hypocenters and magnitudes are archived at the AVO within an AQMS database and in the compressed UNIX tar file that accompanies this publication.

\section{Introduction}

The Alaska Volcano Observatory (AVO) has maintained a catalog of earthquake hypocenters and magnitudes at selected volcanoes in Alaska since October 1989. This effort began with seismic monitoring of two volcanoes in the Cook Inlet region and now covers 32 volcanic centers (fig. 1) making use of more than 200 seismic sensors (fig. 2). The AVO earthquake catalog currently contains more than 120,000 hypocenters and associated magnitudes. The operation of the AVO seismic network, data acquisition, and analysis, as well as the resulting catalog of earthquake hypocenters and magnitudes, are described in a series of reports, the most recent of which is Dixon and others (2013). The principal use of AVO's earthquake catalog is to track earthquake activity at seismically monitored volcanoes to understand volcanic processes and warn of future hazardous volcanic activity.

Over three decades, AVO seismic instrumentation, telemetry, data acquisition, and processing have experienced numerous changes as technology, data formats, processing

\footnotetext{
${ }^{1}$ U.S. Geological Survey.

${ }^{2}$ Instrumental Software Technologies, Inc., New Paltz, New York.

${ }^{3}$ University of Alaska Fairbanks Geophysical Institute.
}

techniques, and software have advanced and evolved. These changes have naturally led to inconsistencies in the AVO earthquake catalog. These inconsistencies include the manner in which earthquake hypocenters and magnitudes have been calculated, the geodetic datum (changed from North American Datum of 1987, NAD 27, to World Geodetic System 1984, WGS 84), the formats and conventions used to store station metadata (location, elevation, and instrumental response), and archival methods for event waveform data. A consistent catalog of earthquake hypocenters and magnitudes is essential for AVO to evaluate future episodes of seismic unrest at active volcanoes in Alaska and to engage in comparative scientific investigations.

In this report, we describe our recent efforts to develop a catalog of earthquake hypocenters and magnitudes recorded between 1989 and 2018 that are calculated as consistently as possible using the earthquake location program Hypoinverse (Klein, 2002; Fred Klein, U.S. Geological Survey, USGS, written commun., 2014) and the Advanced National Seismic System (ANSS) Quake Monitoring System (AQMS) database. The AQMS is derived from software developed as part of the TriNet project (Hauksson and others, 2003). This effort is motivated by AVO's shift to the AQMS on February 1, 2012. This report begins with a review of the seismic instrumentation, telemetry, acquisition systems, processing software, and archival data formats used by AVO from 1989 to the present. We then describe the steps we have taken to load AVO earthquake hypocenters and magnitudes and associated phase, amplitude, and waveforms into the AQMS database. Next, we review the velocity models and configuration of Hypoinverse and AQMS used to calculate earthquake hypocenters and magnitudes at AVO. The report continues with a comparison of the original hypocenters calculated with Hypoellipse (Lahr, 1999) and new hypocenters calculated with Hypoinverse between 1989 and 2012, and concludes with a discussion on the recalculation of magnitudes between February 1, 2012, and January 1, 2018. The compressed UNIX computer operating system tar file (tar stands for tape archive) that accompanies this report (see appendix) contains all of the necessary computer files to calculate earthquake hypocenters and magnitudes using either Hypoellipse (1989 to 2012) or Hypoinverse (1989 to 2018), as well as recalculated hypocenter summary records and system response files. 

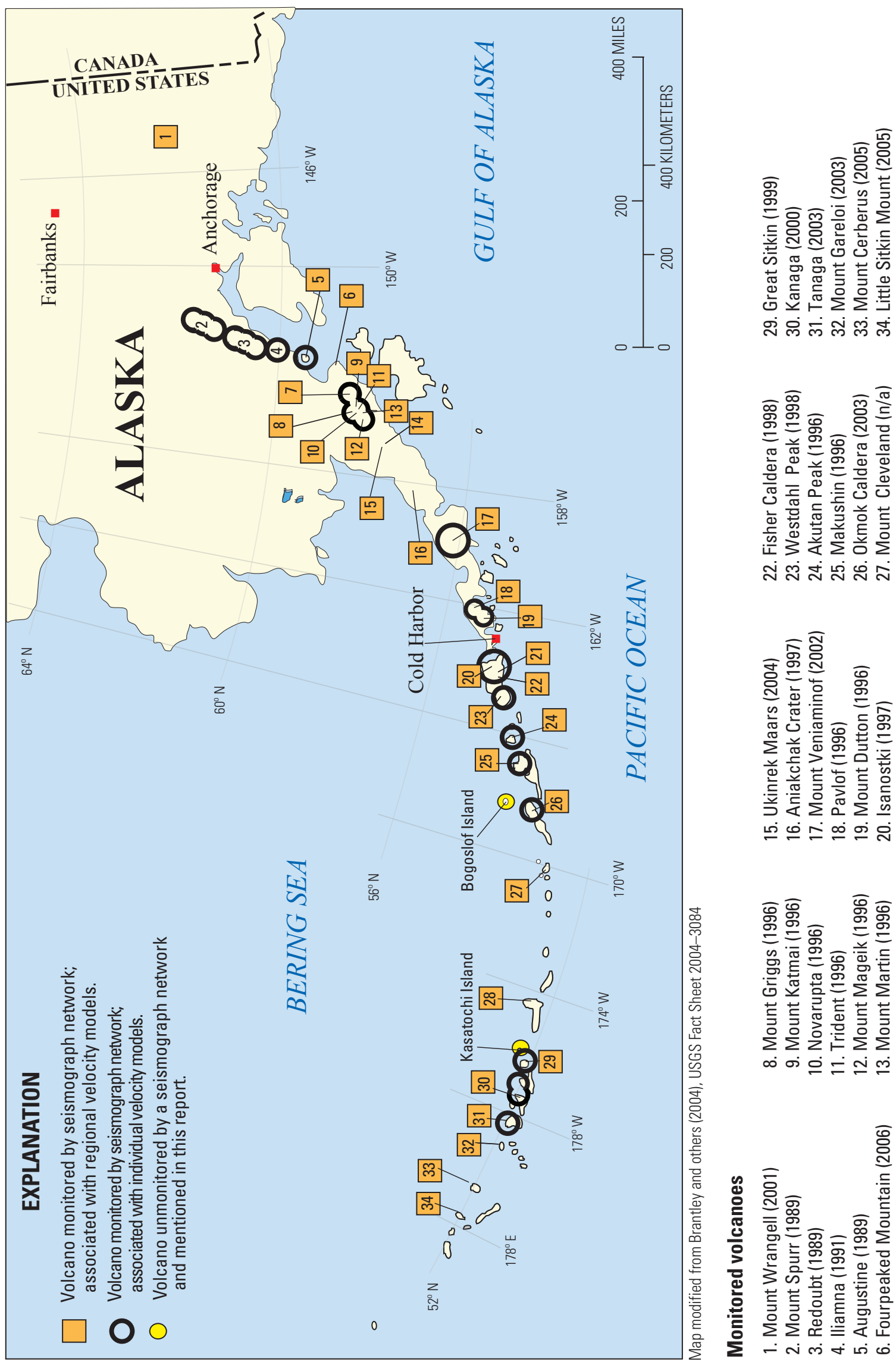

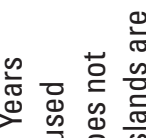

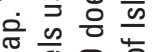
E 응 은 F 들 产응 흘 든

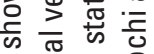
늗 흥 $\frac{0}{E}$ 을 U.

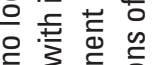

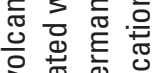

क $\bar{\infty}$ ब

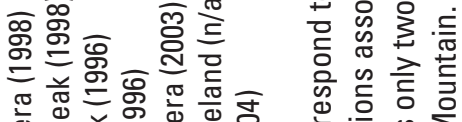

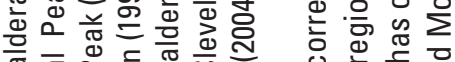

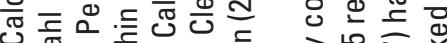

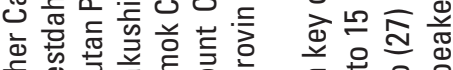

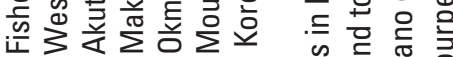

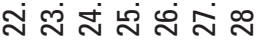

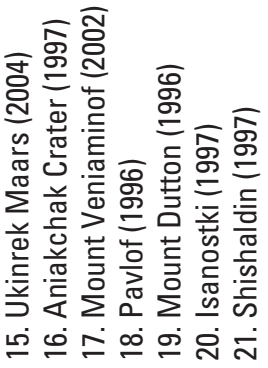

क人

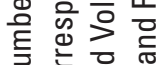

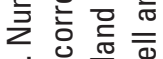

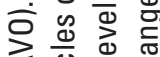

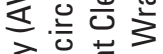

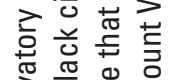

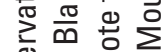
is 2

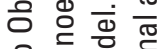
응 덩 응 틀 능 근 즘 퐁 흘 중

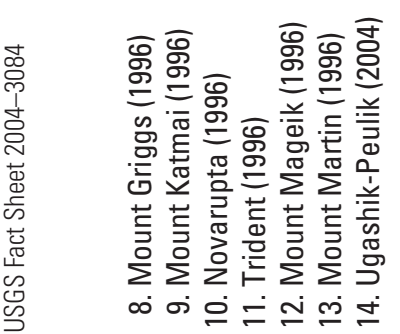

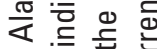
芒芯思

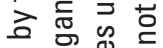
잉 은

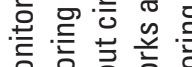

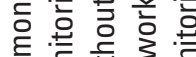

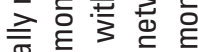

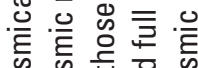

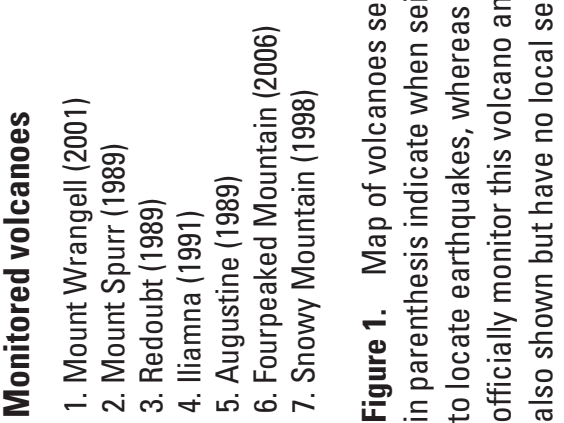




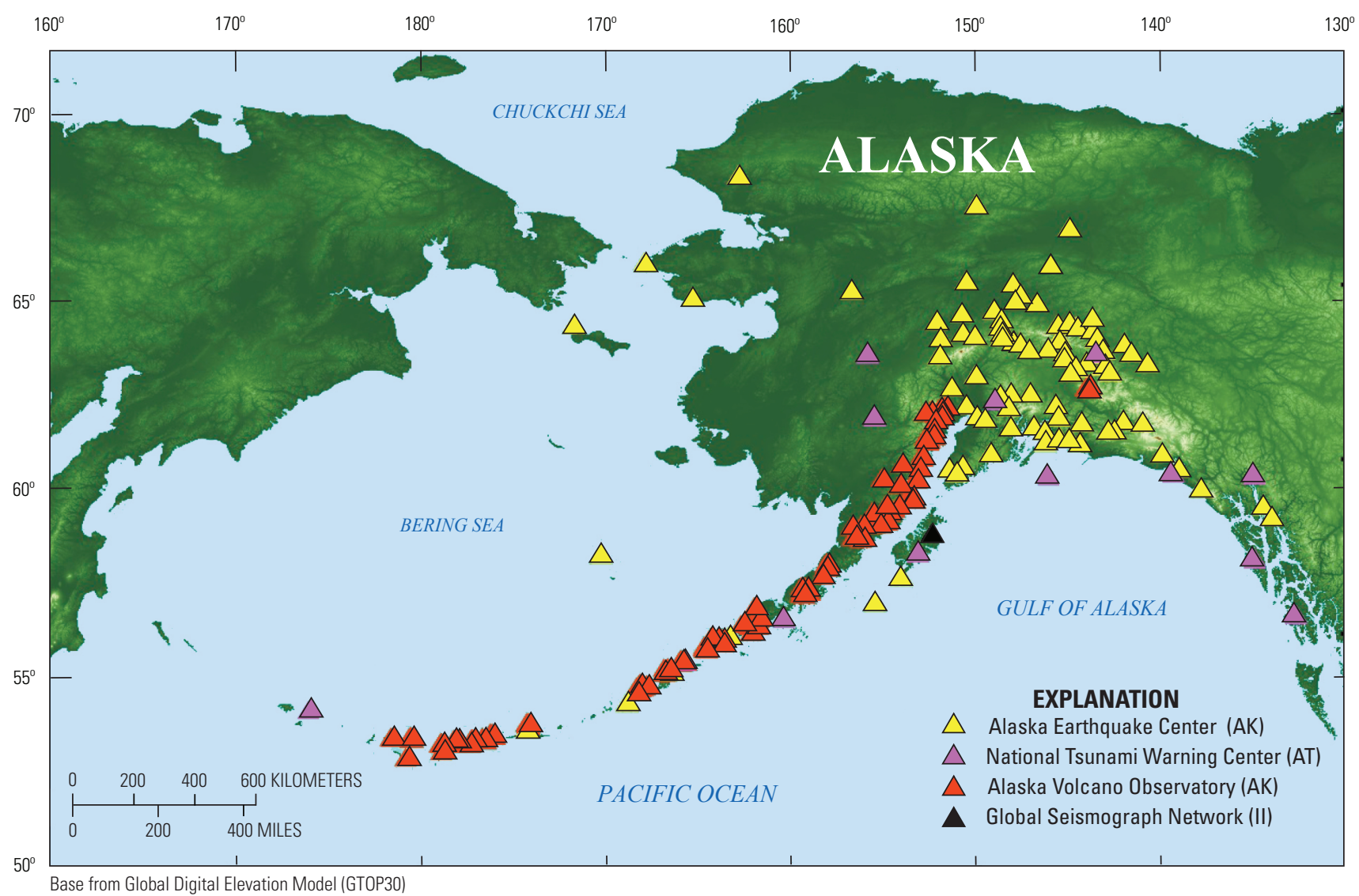

Figure 2. Map of permanent seismic stations operated in Alaska. Network codes are shown in parentheses. Red, Alaska Volcano Observatory (AV); yellow, Alaska Earthquake Center (AK); purple, National Tsunami Warning Center (AT); black, Global Seismograph Network (II).

\section{Earthquake Catalog-Instrumentation, Data Acquisition, and Processing}

The first earthquakes listed in the AVO earthquake cata$\log$ occurred on October 12,1989, and initially only included microearthquakes located at Redoubt Volcano and Mount Spurr (Power and others, 1993). By 2012, AVO had increased the number of volcanoes with suitable seismic instrumentation to locate microearthquakes on 32 volcanoes in Alaska (fig. 1) (Dixon and others, 2013). Generally, a seismically monitored volcano has four or more seismograph stations within 15 kilometers $(\mathrm{km})$ of the volcano's summit, as well as real-time data telemetry. Because of the large number of earthquakes that take place within the Aleutian subduction zone, AVO has only attempted to locate earthquakes within about $50 \mathrm{~km}$ of seismically monitored volcanoes by requiring an S-P wave differential time of 5 seconds or less on the stations closest to the volcanoes' summits. This excludes earthquakes within the Aleutian megathrust (Carver and Plafker, 2008) and in more distant tectonic areas, although occasionally some more distant tectonic earthquakes have been included. The Alaska Earthquake Center (AEC), the National Earthquake
Information Center (NEIC) and the National Tsunami Warning Center locate these earthquakes. These organizations also rapidly report locations and magnitudes of large earthquakes, and AVO does not duplicate these efforts. At times, when large tectonic earthquakes with numerous aftershocks have occurred in the shallow crust within $50 \mathrm{~km}$ of a monitored volcano, AVO has deferred processing to the AEC. AVO occasionally locates earthquakes at volcanoes without a complete, local seismic network of four or more stations. Kasatochi Island and Bogoslof Island (fig. 1), which have no local seismic stations but erupted in 2008 and 2016-17, respectively, and Mount Cleveland, which has only two local seismograph stations, are the volcanoes where this has most notably occurred. These hypocenters are contained in the AVO earthquake catalog and many may also be found in the catalog maintained by the AEC. We plan to make the AVO earthquake catalog available through the ANSS Comprehensive Earthquake Catalog (https://earthquake.usgs.gov/data/comcat/).

Central to the development of the AVO earthquake catalog from 1989 to 2012 was the earthquake location program Hypoellipse (Lahr, 1999). This program was originally written to calculate hypocenters and magnitudes of regional tectonic earthquakes and was modified to locate earthquakes 
in volcanic areas with extreme topography following the 1989-90 eruption of Redoubt Volcano. Specific modifications included the capability to locate earthquakes above the elevation of the seismic stations and assign event classifications such as "volcano tectonic," "long period," and "hybrid" to located events (Lahr and others, 1994). In 2010, Fred Klein modified Hypoinverse by adding the capability to locate hypocenters above the seismic stations and reference hypocentral depths to sea level (Fred Klein, USGS, written commun., 2014).

The AVO seismic network and acquisition and analysis system have changed numerous times between 1989 and 2018, mainly in response to improvements in technology, as well as to the year-2000 computer problem (often referred to as Y2K or the Millennium Bug). For example, in 1989 seismic stations consisted solely of short-period 1 hertz $(\mathrm{Hz})$ seismometers that used FM-radio-based analog telemetry. Event detected waveform data were collected using a 16-channel International Association of Physics of the Earth's Interior (IASPEI) system (Lee and others, 1988). This system ran on a computer using DOS (the "Disk Operating System" used on most IBM PC compatible computers in the 1980s and 1990s) that was not on a network, and the acquisition program had to be stopped to recover waveform files (March and Power, 1990). Processing was done using the waveform-picking program Xpick (Robinson, 1990) and hypocenters and magnitudes were calculated using the program Hypoellipse (Lahr, 1999). The change that most greatly affected the character of the AVO earthquake catalog was the change in the event detection algorithm that accompanied the move from the IASPEI (Lee and others, 1988 ) to the Earthworm system (Johnson and others, 1995) on February 1, 2002. A comparative study of the two systems was performed by Dixon and others (2005) at volcanoes monitored by AVO, and the Earthworm system was found to be more effective at detecting events in volcanic settings using the relatively sparse seismic networks that are typically operated on Alaskan volcanoes. The acquisition and analysis system that AVO currently operates is an Earthworm system/AQMS that became operational on February 1, 2012.

The most significant changes in the acquisition and processing systems between 1989 and 2018 are summarized below.

- October 12, 1989, recording on IASPEI system (Lee and others, 1988) begins, processing is with Xpick and Hypoellipse, and waveform data format is AH (Dost and others, 2012). Geodetic datum is NAD 27.

- January 1, 1993, changed event detection algorithm to XDETECT (Rogers, 1993).

- January 1, 2000, change to the Y2K compliant version of Hypoellipse.

- March 1, 2002, event detection and recording switches to Earthworm, and waveform data format switches to SAC2000 (Goldstein and Snoke, 2005).
- March 1, 2005, station names changed to station, channel, network (SCN) compliant codes (Incorporated Research Institutions for Seismology, 2012), AVO stations use the network code AK and use the extension SHZ for all short-period vertical-seismograph stations.

- November 1, 2005, AVO stations switch to the network code AV and properly assign the extensions EHZ and SHZ to AVO short-period vertical-seismograph stations as appropriate depending on the digitization rate.

- January 11, 2011, started continuous archival of waveform data at Incorporated Research Institutions for Seismology Data Management Center (IRIS DMC) in realtime.

- February 1, 2012, began using AQMS database and switched to Jiggle (Hauksson and others, 2003) and Hypoinverse for processing. Reference datum changes from NAD 27 to WGS 84.

\section{Hypoinverse Configuration}

At AVO, Hypoinverse is configured to most reliably locate small earthquakes in areas of high topography. AVO uses 14 crustal velocity models - 13 of which are for individual volcanoes or volcanic areas. A regional model is used for all earthquakes that fall outside the individual volcano models or at volcanoes where an improved velocity structure has not been determined. Dixon and others (2013), and references therein, describe each individual velocity model. Each model covers a specific geographic area described by single or multiple cylinders. Single cylinders are used at Akutan Peak, Augustine Volcano, Iliamna Volcano, Makushin Volcano, Okmok Caldera, Tanaga Volcano, Mount Veniaminof, and Westdahl Peak. Multiple cylindrical regions are used for velocity models surrounding Mount Katmai, Cold Bay, Redoubt Volcano, Mount Spurr, and the Andreanof Islands (fig. 1).

Velocity models are one-dimensional and consist of a number of layers over a half-space (see https://en.wikipedia. org/wiki/Half-space_(geometry)). The exception is the model for Akutan Peak volcano that uses a linear gradient over a half-space. Hypoinverse uses station elevations to calculate travel time to the stations embedded in the velocity model. In the AVO catalog, hypocentral depth is referenced to sea level with negative depths reflecting height above sea level. The top of each model is set equivalent to the elevation of the summit or highest volcanic peak in the region. The maximum elevation in the regional model is set to $3.2 \mathrm{~km}$, the approximate elevation of Shishaldin Volcano, which is the highest Aleutian volcano. Hypoinverse's capability to set maximum elevation in individual models represents a significant change from Hypoellipse, in which all models were required to have the same maximum elevation above sea level. 
We have configured Hypoinverse to work well with the relatively sparse networks operated by AVO at Aleutian volcanoes and also to match the historical inputs used in Hypoellipse when possible. The principal computational differences between the two algorithms are that Hypoellipse uses a least squares approach (Lahr, 1984), whereas Hypoinverse uses a singular value decomposition (SVD) (Klein, 2002; Fred Klein, USGS, written commun., 2014) to invert for the hypocenter. The two programs also use a very different approach for suppressing the use of stations with poorly fitting residuals and stations that are at great distance from the calculated hypocenter. Hypoinverse progressively down weights stations with large residuals and distance from the calculated hypocenter by dynamically applying a cosine taper function during the calculation of each hypocenter (Klein, 2002; Fred Klein, USGS, written commun., 2014), whereas Hypoellipse requires values for these parameters to be set based on advanced knowledge of the network aperture and geometry.

The AQMS uses the interactive analysis program Jiggle to calculate both local magnitudes and duration magnitudes. Local magnitudes are thought to be more accurate at most AVO networks as a coda-magnitude relation has only been determined for the Cook Inlet region (Lahr, 1999). However, computation of local magnitudes is not always possible because large earthquakes can exceed the dynamic range of short-period stations that are common in AVO networks. Therefore, the reported magnitude is left to the discretion of the data analysts. For this report we recalculate magnitudes between February 1, 2012, and January 1, 2018, to incorporate corrections that were made to individual station response information and the configuration of magnitude calculation in Jiggle after the events were initially processed.

\section{Relocation of Hypocenters-1989-2012}

To relocate hypocenters between October 1989 and February 2012 we loaded waveforms, phase, and station metadata (location, elevation, period of operation, and system response) into the AQMS database and used the "Hypo-Mag" routine developed by Allan Walters (USGS, written commun., 2017).

When earthquake locations, magnitudes, phase arrivals, and waveforms were imported into the AQMS database, the following changes to the data were made to make all information as consistent as possible and bring the data into compliance with Standard for the Exchange of Earthquake Data (SEED) conventions (Incorporated Research Institutions for Seismology, 2012) and with current ANSS processing protocols and standards:

- Added or changed the network codes and component identifier of $\mathrm{EHZ}$ or SHZ, as appropriate, for the station digitization rate to all station data from before March 1, 2005.
- Added location, elevation, and periods of operation for stations without known response information to AQMS station_data and channel_data tables. These stations are listed in table 1.

- Changed the names of stations where original station names were not compliant with SEED conventions. These station names are listed in table 2 .

- Removed phase picks made on pressure sensors (channel code BDF) from the database, as neither Hypoinverse nor Hypoellipse has the capability to make use of atmospheric pressure sensor data.

- Six events between 2012 and 2016 had improper AQMS processing codes - these were corrected.

- Removed phase arrivals for stations HIN and FX01, as each had only one arrival in the entire database, and these stations were more than $500 \mathrm{~km}$ from epicenter of their respective earthquake hypocenters.

Station metadata for the AVO network (network code AV) were compiled into two dataless SEED volumes. The current dataless SEED volume covers the AV network from November 1,2005 , to the present and a historical dataless SEED volume that runs from the 1970s through October 31, 2005. Both of these dataless SEED volumes are contained in the compressed UNIX tar file that accompanies this report (available only online at https; however, the most current dataless volume for the AV network should be obtained from the IRIS DMC (https://ds.iris.edu/pub/RESPONSES/DATALESS_SEEDS/).

There were many stations, especially between 1989 and 2005, for which we were unable to determine the full response, and only locations, elevations, and periods of operation (if known) were entered in the AQMS station_data and channel_data tables. Data from these tables can be found in the computer file that accompanies this report. Many stations installed before 1996 used the A1 voltage control oscillator (A1VCO) (Rogers and others, 1980), which had the capability for variable gain depending upon the strength of the incoming signal. The response characteristics of these instruments cannot be described using the SEED standards (Incorporated Research Institutions for Seismology, 2012). The earthquake location program Hypoellipse (Lahr, 1999) and the visual phase picking program Xpick (Robinson, 1990) were configured to calculate earthquake magnitudes using data from A1VCOs, whereas AQMS processing does not support this capability.

The original hyocenters and magnitudes and all phase data were recovered from October 12, 1989, through February 1, 2012 (fig. 3), which is the period before the use of the AQMS database. Event detected waveforms were also recovered for the entire time period except for 17 days between August 14 and September 1, 1990. Without these waveforms, phase arrivals for this time period cannot be reevaluated or redetermined. 
Table 1. Seismic stations in Alaska with unknown response information (see Dixon and others, 2013, for station locations).

[Station start and end dates are in year/month/day format. AV, stations operated by the Alaska Volcano Observatory; AK, stations operated by the Alaska Earthquake Center; SCN, station, channel, network]

\begin{tabular}{lll}
\hline \multicolumn{1}{c}{ Station (SCN) } & \multicolumn{1}{c}{ Start date } & \multicolumn{1}{c}{ End date } \\
\hline AV_AK3 & $1996 / 03 / 19$ & $1997 / 08 / 08$ \\
AV_AKS & $1996 / 03 / 17$ & $1997 / 08 / 08$ \\
AV_AUC & $1995 / 09 / 13$ & $2001 / 09 / 18$ \\
AV_AUH & $1992 / 08 / 26$ & $2002 / 08 / 25$ \\
AV_AUR & $1995 / 11 / 01$ & $2001 / 09 / 18$ \\
AV_AUS & $1996 / 03 / 17$ & $1997 / 08 / 08$ \\
AV_BGL & $1989 / 08 / 13$ & $2004 / 08 / 02$ \\
AV_BGM & $1978 / 09 / 08$ & $1994 / 06 / 10$ \\
AV_BGR & $1991 / 07 / 01$ & $1999 / 08 / 28$ \\
AV_BKG & $1991 / 07 / 01$ & $2005 / 08 / 30$ \\
AV_CDD & $1992 / 08 / 26$ & $2001 / 09 / 19$ \\
AV_CGL & $1981 / 09 / 22$ & $2000 / 08 / 22$ \\
AV_CKL & $1989 / 08 / 05$ & $2004 / 08 / 10$ \\
AV_CP2 & $1992 / 10 / 23$ & $1997 / 08 / 25$ \\
AV_CPA & $1992 / 01 / 01$ & $1994 / 01 / 01$ \\
AV_CPK & $1991 / 01 / 01$ & $1995 / 01 / 01$ \\
AV_CPKL & $1991 / 01 / 01$ & $1995 / 01 / 01$ \\
AV_CRP & $1981 / 08 / 26$ & $1998 / 08 / 19$ \\
AV_DFR & $1988 / 08 / 15$ & $2000 / 08 / 23$ \\
AV_DFS & $1990 / 01 / 01$ & $1995 / 01 / 01$ \\
AV_DRE & $1990 / 01 / 01$ & $1995 / 01 / 01$ \\
AV_ILI & $1987 / 09 / 15$ & $2001 / 09 / 22$ \\
AV_INW & $1990 / 01 / 01$ & $1995 / 01 / 01$ \\
AV_KDC & $1995 / 08 / 29$ & $2005 / 11 / 01$ \\
AV_MMN & $1995 / 02 / 22$ & $1999 / 09 / 11$ \\
AV_NCG & $1989 / 08 / 06$ & Present $(2018)$ \\
AV_NCT & $1988 / 08 / 14$ & $2000 / 08 / 23$ \\
AK_NNL & $1989 / 01 / 01$ & $1995 / 01 / 01$ \\
AV_PDB & $1978 / 08 / 09$ & $1999 / 09 / 15$ \\
AV_RDN & $1988 / 08 / 13$ & $2004 / 09 / 18$ \\
AV_RED & $1999 / 08 / 28$ & $2002 / 08 / 27$ \\
AV_REF & $1992 / 07 / 27$ & $2000 / 08 / 22$ \\
AV_RDT & $1971 / 08 / 09$ & $2003 / 08 / 07$ \\
AV_RDW & $1990 / 09 / 07$ & $1996 / 03 / 17$ \\
AV_RS1 & $1990 / 01 / 01$ & $1995 / 01 / 01$ \\
AV_RS2 & $1990 / 01 / 01$ & $1995 / 01 / 01$ \\
AV_RSO & $1990 / 03 / 01$ & $1999 / 08 / 18$ \\
AV_RWS & $1990 / 01 / 01$ & $1995 / 01 / 01$ \\
AV_SPU & $1971 / 08 / 10$ & $1998 / 08 / 11$ \\
\hline & &
\end{tabular}

Table 2. Stations with noncompliant component names and the new name used in the Advanced National Seismic System (ANSS) Quake Monitoring System (AQMS) (see Dixon and others, 2013, for station locations).

\begin{tabular}{lc}
\hline Original station name & New station name in AQMS \\
\hline ACHE & AV ACH EHE \\
ACHN & AV ACH EHN \\
AKSE & AV AKS EHE \\
AKSN & AV AKS EHN \\
AKTE & AV AKT EHE \\
AKTN & AV AKT EHN \\
AUD- & AV AUD ELZ \\
AUIE & AV_AUIEHE \\
AUIN & AV_AU_EHN \\
AUDL & AV_AUD_ELZ \\
CPAE & AV_CPA_EHE \\
CPAN & AV_CPA_EHN \\
CRPE & AV_CRP_EHE \\
CRPN & AV_CRP_EHN \\
IVEE & AV IVE EHE \\
IVEN & AV IVE EHN \\
KCEL & AV KCE ELZ \\
KCGE & AV KCG EHE \\
KCGN & AV KCG EHN \\
MSWE & AV MSW EHE \\
MSWN & AV MSW EHN \\
PV6E & AV PV6 EHE \\
PV6N & AV PV6 EHN \\
REDE & AV RED EHE \\
REDN & AV RED EHN \\
REFE & AV REF EHE \\
REFL & AV REF ELZ \\
REFN & AV REF EHN \\
REF- & AV REF ELZ \\
\hline & \\
& \\
&
\end{tabular}

The steps followed to recalculate hypocenters involved running the Hypomag routine, which recalculates the hypocenter and magnitude and inserts the result in the AQMS database, twice for each catalog year. Missing stations in the dataless SEED volume are checked for after the first run, and if found, the metadata is corrected either in the dataless SEED volume if response information was known, or in the AQMS database if not. Locations where the hypocenter or depth changed by more than $15 \mathrm{~km}$ were also checked. If possible, these solutions were corrected, often by adjusting incorrect phase picks before the second run of Hypomag. 


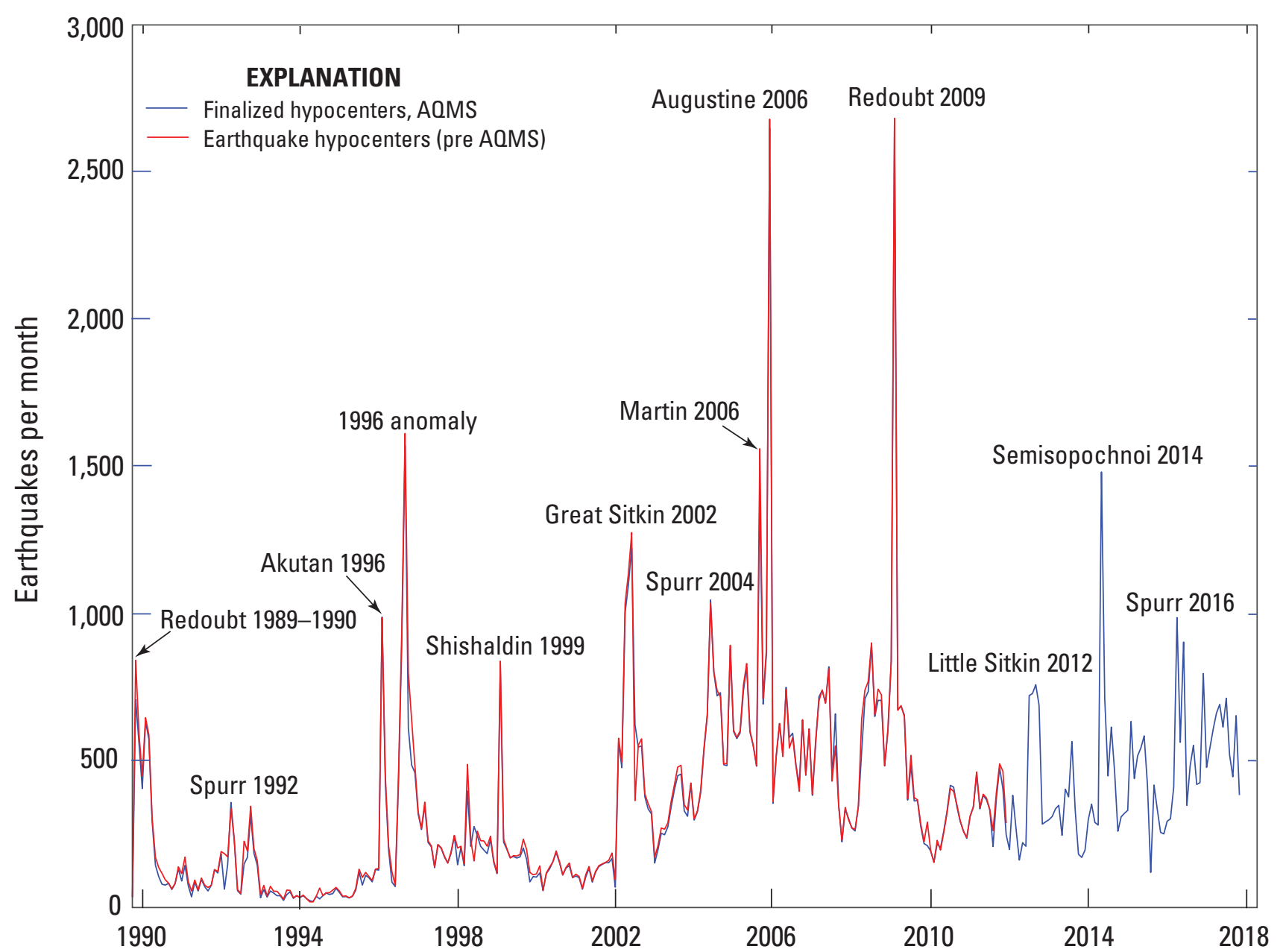

Figure 3. Graph showing number of earthquakes located by the Alaska Volcano Observatory (AVO) each month from October 1989 through December 2017. Blue line shows the number of finalized earthquake hypocenters in the AVO Advanced National Seismic System (ANSS) Quake Monitoring System (AOMS) database, and the red line shows the number of earthquakes located by AVO between October 1989 and February 1, 2011, as recovered from AVO data archives. This provides a check on the completeness of the hypocenter data loaded into the AOMS database. Minor discrepancies likely result from changes in the quality criteria used to finalize earthquake hypocenters. Volcanic events that were associated with large increases in the number of located earthquakes are noted within the graph. Increases in the number of located earthquakes in 1996 and 2002 roughly reflect expansion of the AVO seismographic network. Volcano names are abbreviated; see figure 1 for complete names. See McNutt and Marzocchi (2004) for further discussion of the 1996 anomaly.

\section{Comparison of Hypoellipse and Hypoinverse Hypocenters}

Visual comparisons were made of epicenter maps and cross sections from Redoubt Volcano (fig. 4), Akutan Peak volcano (fig. 5), Tanaga Volcano (fig. 6), and Okmok Caldera (fig. 7) for selected time periods to qualitatively evaluate relocated hypocenters. We chose hypocenters at Redoubt in December 1989 (fig. 4) for this comparison, because the phase arrivals were carefully reviewed (Lahr and others, 1994) and the velocity structure was determined by an active source seismic experiment (Benz and others, 1996). Akutan, Tanaga, and Okmok were selected because these volcanoes had numerous hypocenters that occur both within and outside of the local network (figs. 5-7). These plots suggest that the overall spatial distribution of earthquake hypocenters did not change significantly as a result of relocation with Hypoinverse.

The change in depth, epicenter and hypocenter was calculated for every earthquake in the AVO catalog before February 1, 2012, to provide a quantitative comparison of Hypoellipse and Hypoinverse. To make these calculations, we first converted the datum for hypocenters calculated with Hypoellipse from NAD 27 to WGS 84. The epicentral position was then calculated using the technique given by Stein and Wysession (2003). The Pythagorean theorem was used to calculate the change in position for each hypocenter. For this comparison, we did not include hypocenters that Hypoellipse placed above sea level, because the datum used by Hypoellipse is restricted 

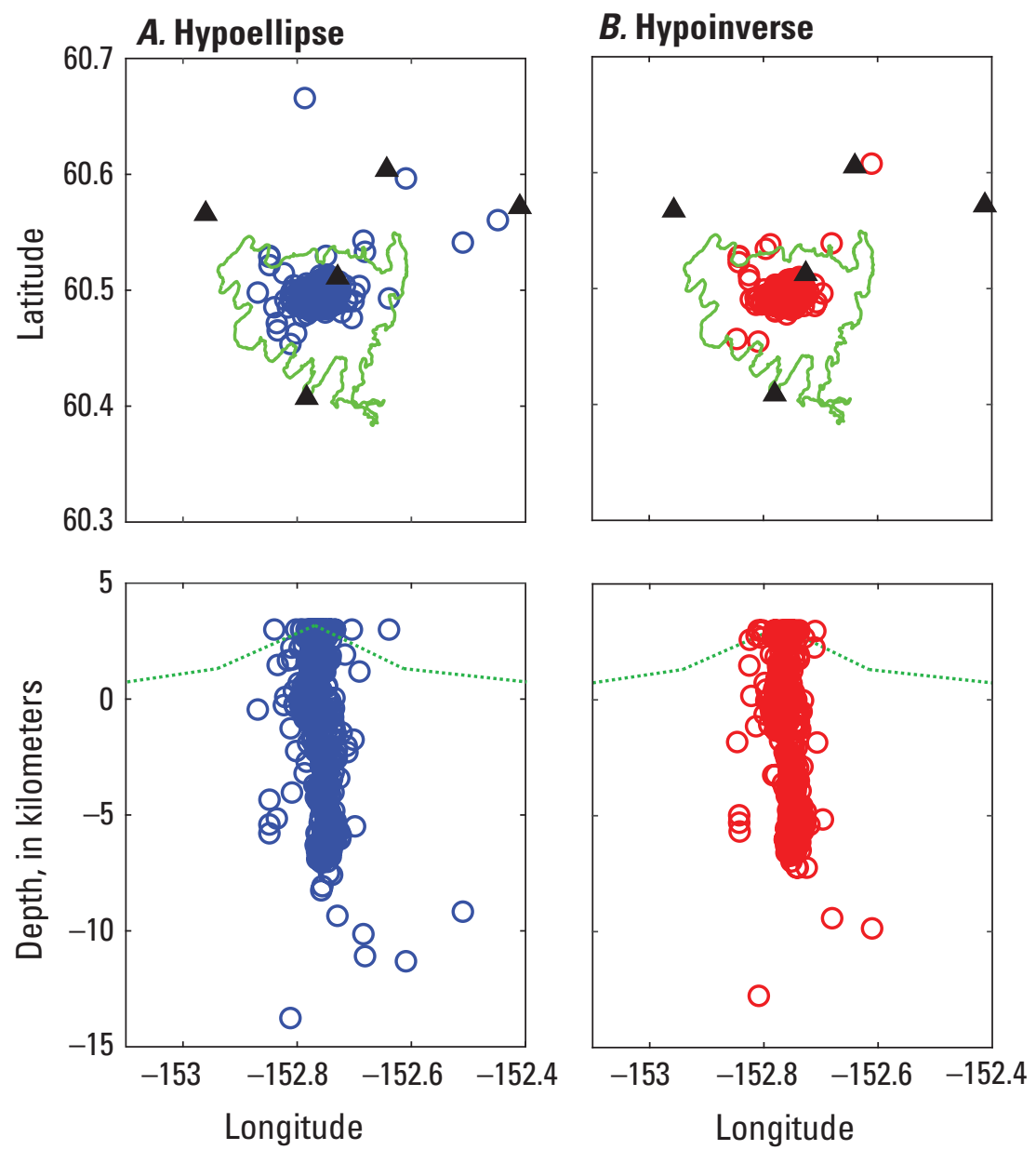

EXPLANATION

O Hypoellipse

O Hypoinverse

- Seismic stations

- Elevation contour (3,000 feet) surrounding Redoubt volcanic cone

-..- Approximates local topography

Figure 4. Simplified map and east-west cross-section showing hypocenters at Redoubt Volcano, Alaska, during December 1989 determined by (A) Hypoellipse and (B) Hypoinverse. Green line in map view corresponds to the 3,000-foot elevation contour surrounding Redoubt's volcanic cone, and the green dotted line in the cross section approximates local topography. Triangles note the seismic stations used to calculate earthquake hypocenters. Volcano location is shown on figure 1. 


\section{A. Hypoellipse}

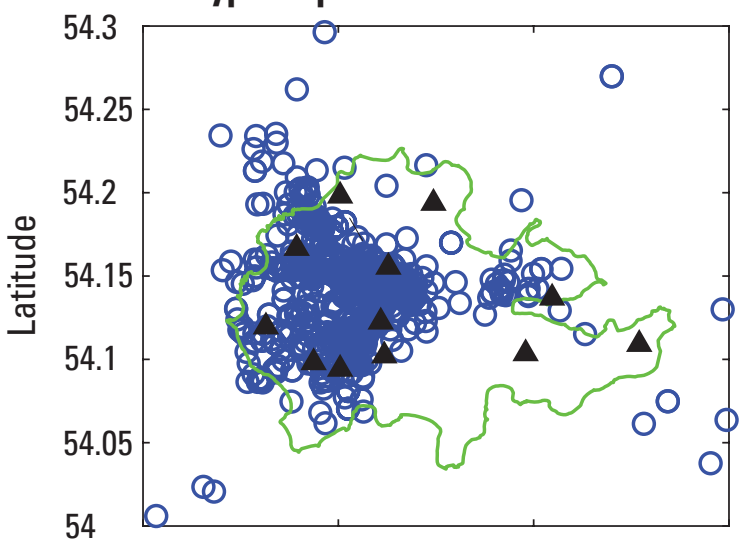

\section{B. Hypoinverse}

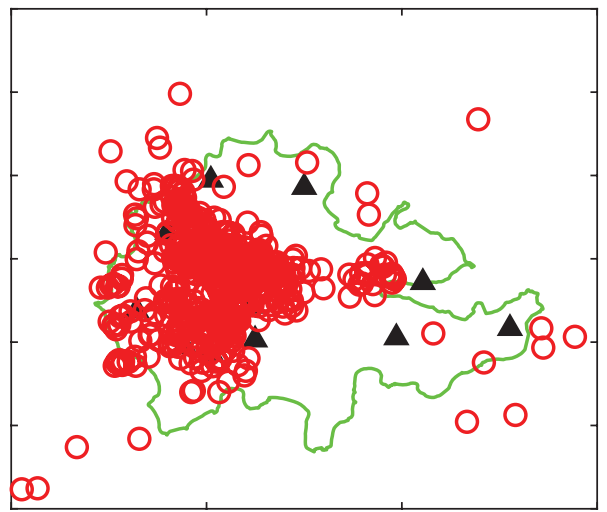

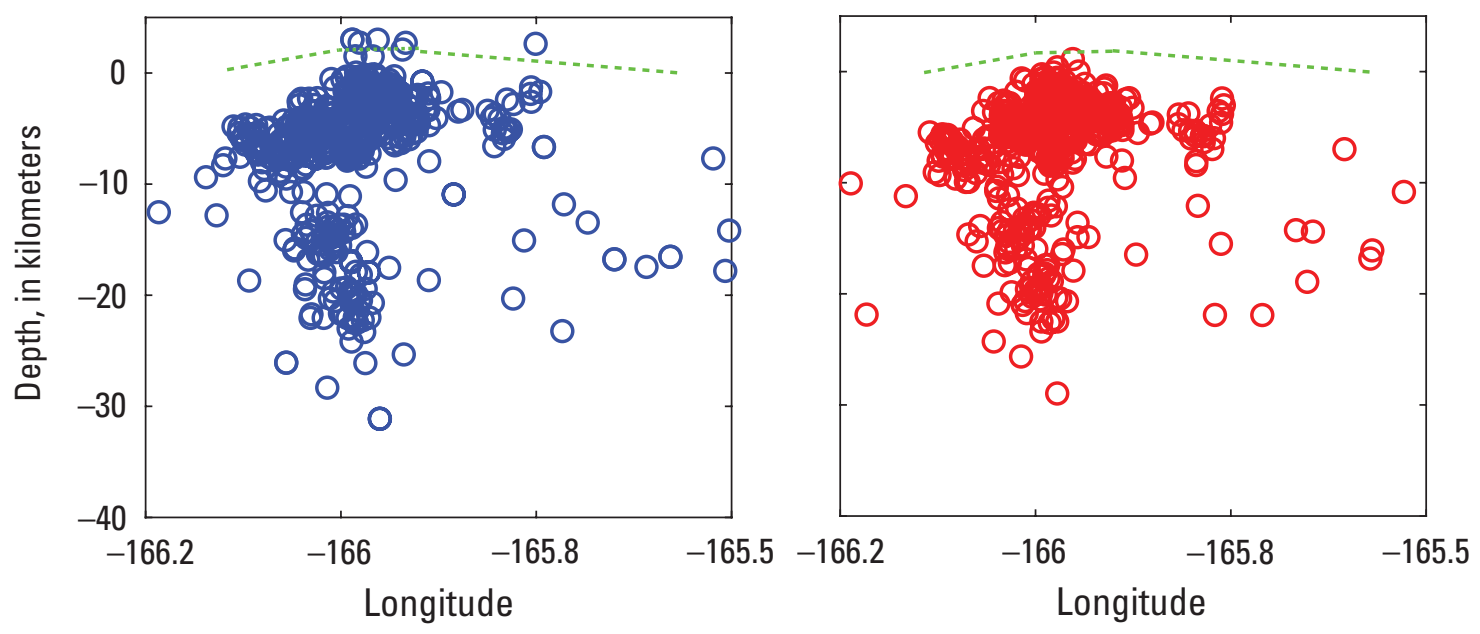

\section{EXPLANATION}

O Hypoellipse

O Hypoinverse

- Seismic stations

_ Coastline of Akutan Island

..-- Approximates local topography

Figure 5. Simplified map and east-west cross-section showing hypocenters at Akutan Peak volcano, Alaska, between January 1, 2000, and January 1, 2011, determined by (A) Hypoellipse and (B) Hypoinverse. Green line in map view corresponds to the coastline of Akutan Island, and green dotted line in the cross section approximates local topography. Triangles note the seismic stations used to calculate earthquake hypocenters. Volcano location is shown on figure 1. 
A. Hypoellipse
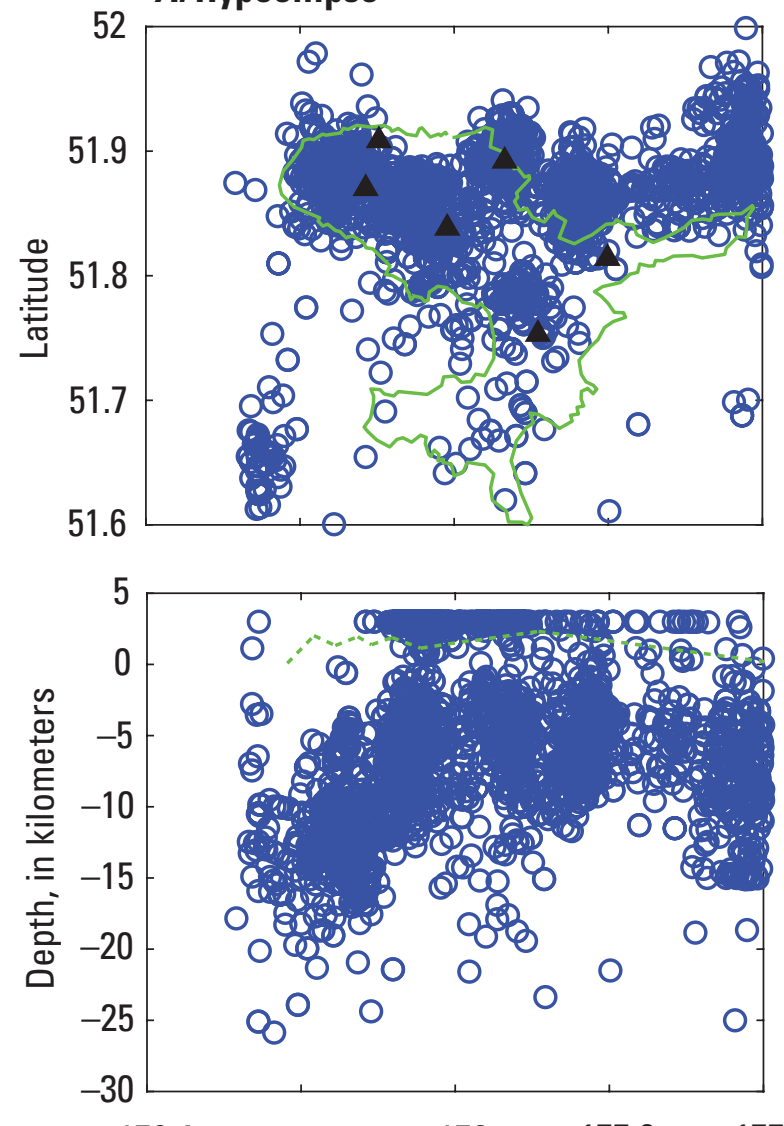

B. Hypoinverse

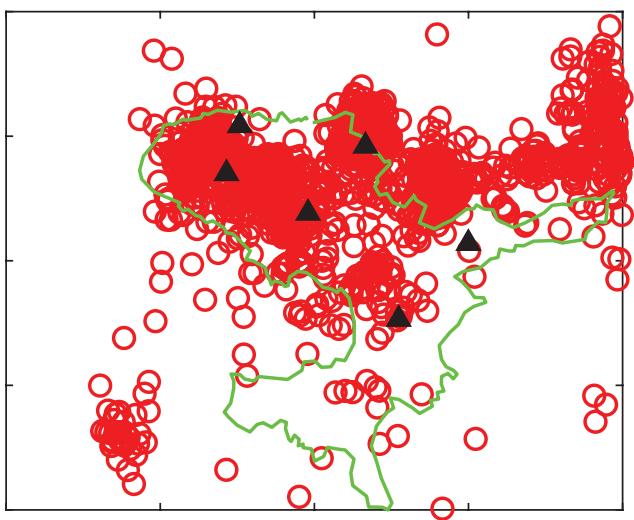

$\begin{array}{rrrrrrr}-178.4 & -178.2 & -178 & -177.8 & -177.6-178.4 & -178.2 & -178 \\ \text { Longitude } & & & -177.8 & -177.6\end{array}$

\section{EXPLANATION}

O Hypoellipse

O Hypoinverse

- Seismic stations

- Coastline of Tanaga Island

-..- Approximates local topography

Figure 6. Simplified map and east-west cross-section showing hypocenters at Tanaga Volcano, Alaska, between January 1, 2000, and January 1, 2011, determined by (A) Hypoellipse and (B) Hypoinverse. Green line in map view corresponds to the coastline of Tanaga Island, and green dotted line in the cross section approximates local topography. Triangles note the seismic stations used to calculate the earthquake hypocenters. Volcano location is shown on figure 1. 


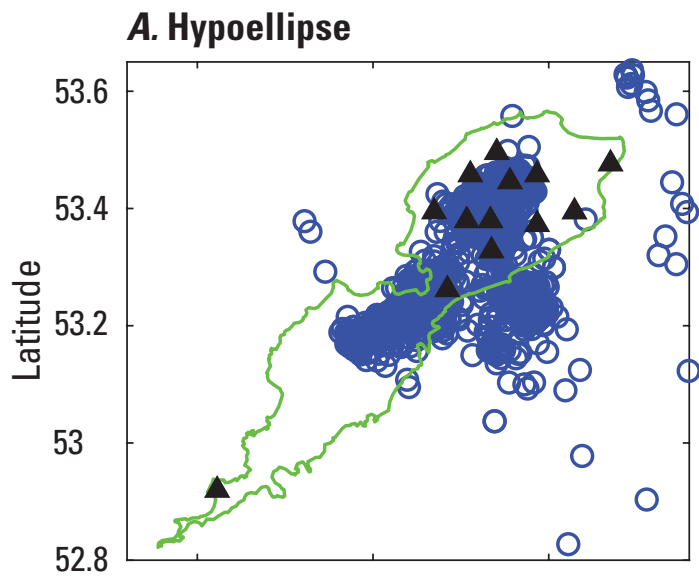

\section{B. Hypoinverse}
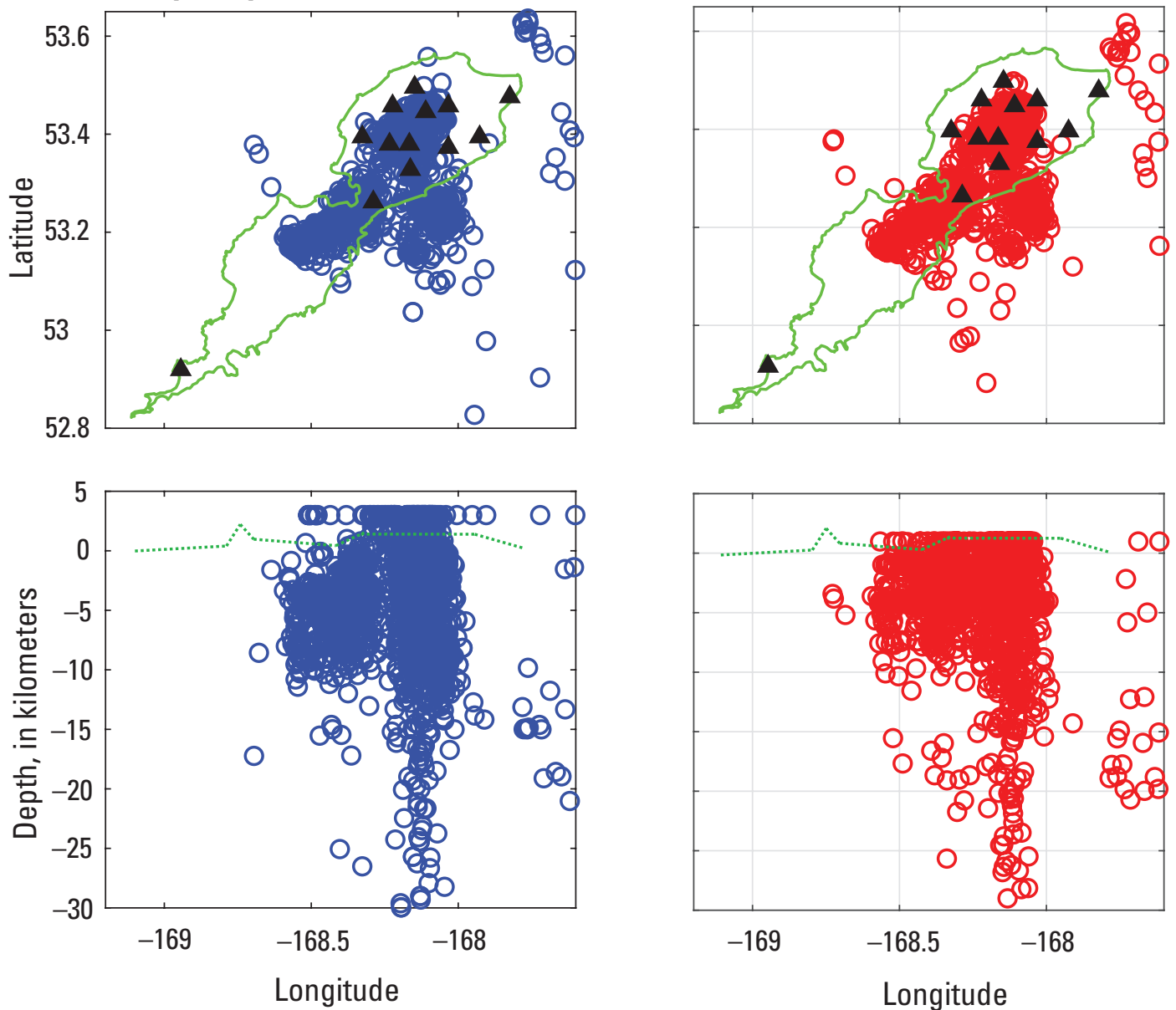

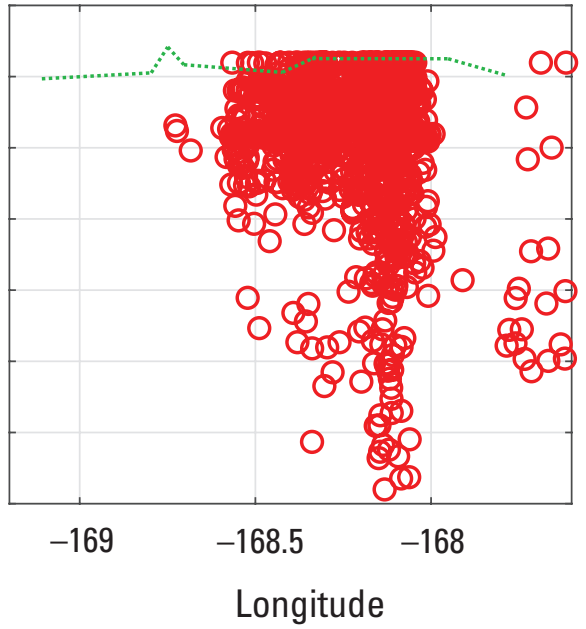

Longitude

\section{EXPLANATION}

O Hypoellipse

O Hypoinverse

- Seismic stations

— Coastline of Umnak Island

-..-Approximates local topography

Figure 7. Simplified map and east-west cross-section showing hypocenters at $0 \mathrm{kmok}$ Caldera, Alaska, between January 1, 2000, and January 1, 2011, determined by (A) Hypoellipse and (B) Hypoinverse. Green line in map view corresponds to the coastline of Umnak Island, and green dotted line in the cross section approximates local topography. Triangles note the seismic stations used to calculate the hypocenters. Volcano location is shown on figure 1. 
to a single value for all volcanoes. Hypoinverse allows this to be set individually for each volcano with an individual velocity model making a direct comparison of this subset of hypocenters meaningless.

The calculated changes in depth, epicenter, and hypocenter for each earthquake are shown in figure 8 . The average changes in depth, epicenter, and hypocenter are $-0.008,1.19$, and $1.85 \mathrm{~km}$, and the first standard deviations are $2.10,1.88$, and $2.43 \mathrm{~km}$ respectively. These relatively small changes in depth, epicenter, and hypocentral position give us some confidence that both the Hypoellipse and Hypoinverse algorithms have worked well in locating earthquakes using the relatively sparse networks of 4 to 15 stations that AVO operates.

These results provide some measure of our ability to determine the absolute location of the earthquake hypocenter. The earthquakes that moved the greatest distance were regional earthquakes that are located 50 to $200 \mathrm{~km}$ from the nearest stations. It is not surprising that these earthquakes move a great distance, because Hypoinverse uses a different default approach than does Hypoellipse for suppressing distant stations and those with poorly defined phases (Fred Klein, U.S. Geological Survey, USGS, written commun., 2017). Because the AVO is primarily interested in locating microearthquakes at hypocentral distances of less than $50 \mathrm{~km}$, input parameters have not been tuned in either Hypoellipse or Hypoinverse for location of distant hypocenters. Through processing, it was discovered that 16 earthquakes occurred between 2005 and 2011 that took place in the eastern hemisphere where the hypocenter was incorrectly placed in the corresponding location in the western hemisphere. We recalculated locations for these "mirrored" hypocenters and placed them correctly back in the eastern hemisphere. The Hypoinverse code has since been corrected so that earthquakes will be located in the correct hemisphere (Fred Klein, USGS, written commun., 2017).

\section{Recalculation of Magnitudes}

The catalog is broken into two time periods from October 1989 through January 2011 and from February 2011 through December 2017 for the purpose of magnitude determination. For magnitude determination, we break the catalog into two time periods from October 1989 through January 2011 and from February 2011 through December 2017. Magnitudes were not recalculated for the first time period because of the use of the A1VCO and lack of complete response information for many seismic stations used by AVO during this time period, rather the original magnitudes calculated by Hypoellipse were saved in the AQMS database. We recognize that some hypocenters for these events may have changed by the relocation with Hypoinverse (Klein, 2002; Fred Klein, USGS, written commun., 2014) and that this could affect the calculated magnitude. However, most of the hypocenters close to volcanoes only moved a small amount (fig. 8) and this change would not significantly alter the existing magnitude.
$\boldsymbol{A}$

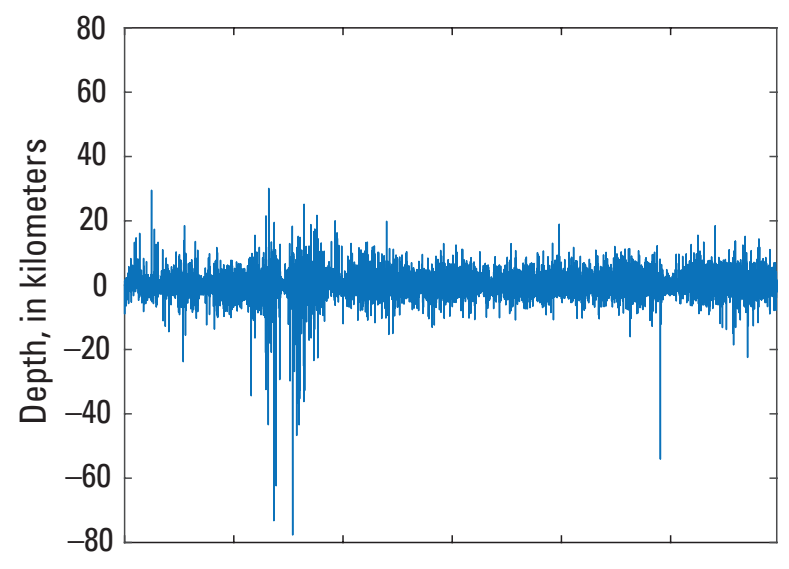

B

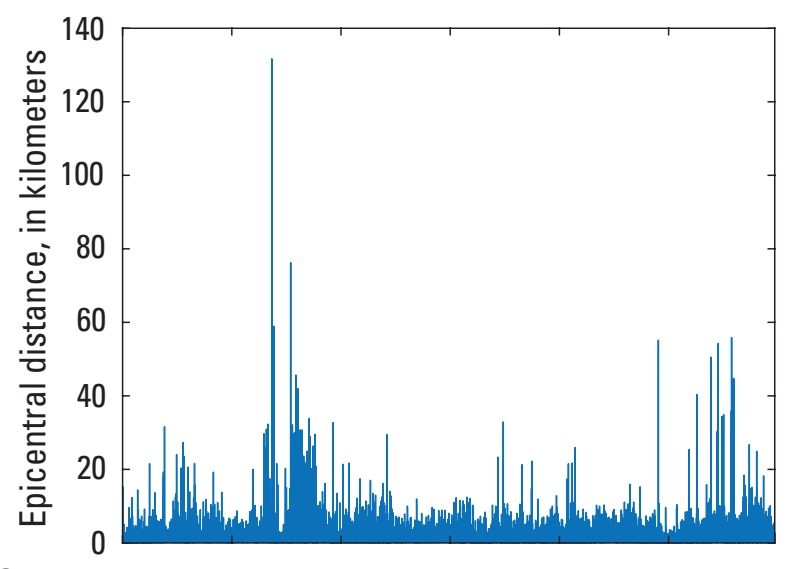

C

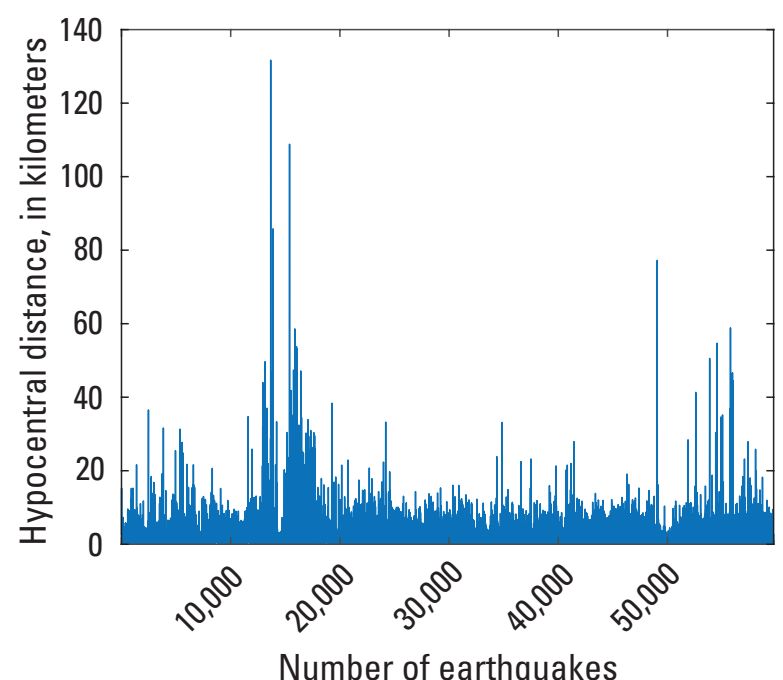

Figure 8. Graphs showing calculated changes in the position of earthquakes located by the Alaska Volcano Observatory between October 1989 and February 1, 2012, when relocated with Hypoinverse. Only earthquakes with hypocenters below sea level are included. The average change in (A) depth, (B) epicenter, and (C) hypocenter are $-0.008,1.19$, and 1.85 kilometers $(\mathrm{km})$ with accompanying first standard deviations of $2.10,1.88$, and $2.43 \mathrm{~km}$, respectively. 
From February 1, 2012, through December 31, 2017, magnitudes were calculated using the interactive analysis computer program Jiggle (Hauksson and others, 2003). Jiggle provides the capability to calculate both duration and local magnitude. At AVO, the local magnitude is set as the preferred magnitude unless clipped data from short-period stations prohibits the calculation of local magnitude. The coda-duration relationship developed by Lahr (1999) only used data from the Cook Inlet region and may not be appropriate for earthquakes on the Alaska Peninsula and Aleutian Islands. Local magnitudes are calculated using the standard formula given by Richter (1958). Hypocenters were recalculated during this time to correct for changes in station metadata and corrections to the inputs for velocity models. The change in calculated magnitudes through time is shown by year in figure 9 . We subtracted the new magnitude from the old magnitude, so that a positive difference reflects a reduction in the newly calculated magnitude. The average change in magnitude for the time period is 0.08 with a standard deviation of 0.31 .

The most obvious corrections in magnitude between February 1, 2012, and December 31,2017, resulted from changes to the methodology and configuration of the Jiggle processing software (fig. 9). These occurred on April 3, 2014, when AVO changed the parameters in Jiggle to only use amplitude measurements on stations that had phase arrivals used in the solution and on June 25, 2015, when the Jiggle property RichterMLMagMethod2 was altered to allow interpolation as suggested by Allan Walter (USGS, written commun., 2017).

Most smaller deviations in magnitude (fig. 9) likely result from corrections in system response information caused by field instrumentation or data recording systems that were not updated in the appropriate AQMS input files at the time of the change. The most significant source of error of this type was a change in analog to digital (AtoD) cards in the Earthworm computers in Anchorage on May 11, 2012, and on Adak on June 21, 2012, respectively. The error was not noticed when all stations underwent this change to AtoD cards A notable example of miscalculated magnitudes is a swarm of earthquakes that occurred on Umnak Island southwest of Okmok Caldera in the fall of 2013 (Dixon and others, 2015) that is illustrated as a strong offset in figure 9. The reduction in magnitudes of the swarm on Umnak are a result of corrections in system response caused by the change in the AtoD card in Anchorage on May 11, 2012. A similar source of error occurred when we deployed short-period seismometers coupled with modern digitizers between 2012 and 2018 . When these new stations were deployed, the accompanying change in system response was not fully understood. Adjustments to the response information were only made after the fact and corrected by the new magnitude calculations reported here. Earthquakes with large ( 2 to 4 magnitude units) negative changes in figure 9 typically correspond to regional earthquakes (magnitude 2.0 to 3.8 ) that have few phase arrivals, locate far from individual volcanoes, and were improperly assigned magnitudes of 0.00 by Jiggle. The improper assignment of magnitude 0.00 occurred in Jiggle when an insufficient number of local stations calculated a magnitude (likely because of electronic clipping) and distant stations were excluded. This occurs in the Aleutian Islands when only short-period stations are present and distances between volcano networks are large. We have since reconfigured Jiggle to avoid this scenario.

\section{Structure of the Accompanying Data File}

The UNIX tar file that accompanies this report (see appendix) contains phase information and necessary input files to recalculate earthquake hypocenters for either Hypoellipse (1989-2011) or Hypoinverse (1989-2017). The tar file also contains Hypoellipse and Hypoinverse summary files from 1989 through 2011 and 1989 through 2017, respectively. There are four subdirectories in the tar file called Hypoe, Hypoi, Summary, and Response that contain input files for Hypoellipse, Hypoinverse, Hypoellipse and hypoinverse summary files, and dataless SEED volumes, respectively. The Hypoi directory contains further subdirectories with input files for use before and after November 1, 2005.

\section{Summary and Conclusions}

Comparison of earthquake hypocenters calculated using Hypoellipse and Hypoinverse between 1989 and 2012 show that the locations from the two algorithms closely match one another at volcanoes in Alaska. The average change in depth, epicenter, and hypocenter are $-0.08,1.19$, and $1.85 \mathrm{~km}$, and the first standard deviation is $2.10,1.88$, and $2.43 \mathrm{~km}$, respectively. This result suggests that both Hypoellipse and Hypoinverse work well for locating earthquakes at volcanoes monitored by AVO and that the earthquake catalog locations are sufficient for general comparative analysis typically done by a volcano observatory to diagnose seismic unrest. The hypocenters in the AVO catalog may be further improved by use of other location or relocation algorithms that are currently in common use in seismology. Recalculated earthquake magnitudes between February 1, 2012, and December 31, 2016, based on improved station response information, resulted in an average change for the 31,925 events of 0.08 with a standard deviation of 0.31 (fig. 9).

Although we have made efforts to search for errors in earthquake hypocenters and magnitudes, missing waveforms in the AQMS database, and incorrect system response information, some errors and omissions certainly remain in the information described in this report. This is a result of the many tasks involved in assembling an earthquake catalog and associated waveforms that rely on a complex system of response information over an almost 28-year period. We suggest that investigators using this information check it for 

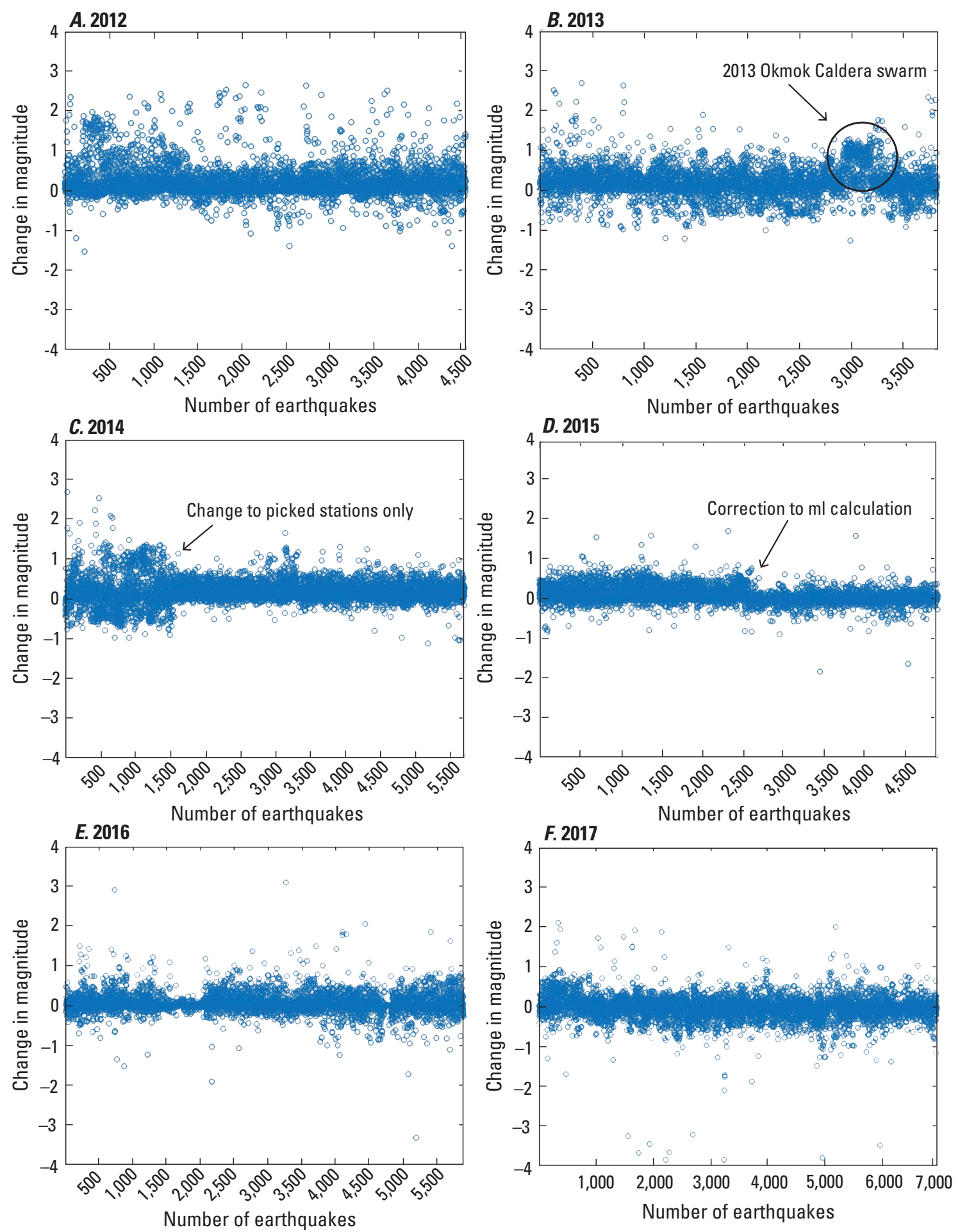

Figure 9. Graphs showing changes in calculated magnitude by year for earthquakes located by the Alaska Volcano Observatory (AVO) from February 1, 2012, through December 31, 2017 (A-F). The calculated change reflects the new magnitude subtracted from the original magnitude, so a positive change reflects a reduction in the assigned magnitude. Major improvements in magnitude calculation were achieved on April 3,2014 , when AVO began only using stations that used P- or S-phases in the hypocenter determination. Major improvements were also achieved on June 25, 2015, when the Jiggle computer program (Hauksson and others, 2003) property RichterMLMagMethod2 was changed to allow interpolation. See text for discussion of the 2013 Okmok Caldera earthquake swarm. 
consistency and completeness relative to their individual requirements and recalculate the hypocenters and magnitudes as needed. Please inform us if any significant inconsistencies or data gaps are discovered.

\section{References Cited}

Benz, H.M., Chouet, B.A., Dawson, P.B., Lahr, J.C., Page, R.A., and Hole, J.A., 1996, Three-dimensional P and S wave velocity structure of Redoubt Volcano, Alaska: Journal of Geophysical Research—Solid Earth, v.101, p. 8111-8128.

Carver, G., and Plafker, G., 2008, Paleoseismicity and neotectonics of the Aleutian subduction zone-an overview in Freymueller, J.T., Haeussler, P.J., Wesson, R.L., Ekstrom, G., eds., AGU Geophysical Monograph Series, v. 179, p. 43-63.

Dixon, J.P., Cameron, C., McGimsey, R.G., Neal, C.A., and Waythomas, C., 2015, 2013 Volcanic activity in AlaskaSummary of events and response of the Alaska Volcano Observatory: U.S. Geological Survey Scientific Investigations Report 2015-5110, 92 p., https://doi.org/10.3133/ sir20155110.

Dixon, J.P., Power, J.A., and Stihler, S.D., 2005, A comparison of seismic event detection with IASPEI and Earthworm acquisition systems at Alaskan volcanoes: Seismological research Letters, v. 76, no. 2, p. 168-176.

Dixon, J.P., Stihler, S.D., Power, J.A., Haney M.M., Parker, T., Searcy, C.K., and Prejean, S., 2013, Catalog of earthquake hypocenters at Alaskan volcanoes-January 1 through December 31, 2012: U.S. Geological Survey Data Series 789, 84 p., https://doi.org/10.3133/ds789.

Dost, B., Zednik, J., Havskov, J., Willemann, R.J., and Borman, P., 2012, Seismic data formats, archival and exchange in Borman, P., ed., New Manual of Seismological Observatory Practice 2 (NMSOP-2), Potsdam: DeutschesGeoForschungsZentrum GFZ, p. 1-4.

Goldstein, P., and Snoke A., 2005, SAC Availability for the IRIS community, Incorporated Institutions for seismology data management center electronic newsletter. V. 7. accessed April 3, 2019 at http://ds.iris.edu/ds/newsletter/ vol7/nol/

Hauksson, E., Jones, L.M., and Shakal, A., 2003, TriNetA modern ground motion seismic network, in Lee, W., Kanamori, H., Jennings, P., and Kisslinger, C., eds., International Handbook of Earthquake and Engineering Seismology, v. 81B, p. 1275-1284.
Incorporated Research Institutions for Seismology, 2012, Standard for the Exchange of Earthquake Data (SEED) reference manual: International Federation of Digital Seismograph Networks, SEED versions format 2.4, 220 p., available at https://www.fdsn.org/seed_manual/SEEDManual_V2.4.pdf.

Johnson, C.E., Bittenbinder, A., Bogaert, D., Dietz, L., and Kohler, W., 1995, Earthworm-A flexible approach to seismograph network processing: Incorporated Research Institutions for Seismology Newsletter, v. 14, no. 2, p. 1-4.

Klein, F.W., 2002, User's guide to HYPOINVERSE-2000, a Fortran program to solve for earthquake locations and magnitudes: U.S. Geological Survey Open-File Report 02-171, 123 p., https://doi.org/10.3133/ofr02171.

Lahr, J.C., 1984, Description of the weighted regression and quality estimation used in the earthquake location program Hypoellipse: U.S. Geological Survey Open-File Report 84-766, 35 p., https://doi.org/10.3133/ofr84766.

Lahr, J.C., 1999, revised 2012, HYPOELLIPSE: a computer program for determining local earthquake hypocentral parameters, magnitude, and first-motion pattern: U.S. Geological Survey Open-File Report 99-23, version 1.1, 119 p. and software, https://doi.org/10.3133/ofr9923.

Lahr, J.C., Chouet, B.A., Stephens, C.D., Power, J.A., and Page, R.A., 1994, Earthquake classification, location, and error analysis in a volcanic environment-Implications for the magmatic system of the 1989-1990 eruptions at Redoubt Volcano, Alaska: Journal of Volcanology and Geothermal Research, v. 62, p. 137-151.

Lee, W.H.K., Tottingham, D.M., and Ellis, J.O., 1988, A PCbased seismic data acquisition and processing system: U.S. Geological Survey Open-File Report 88-751, 31 p., https:// doi.org/10.3133/ofr88751A.

March G.D., and Power, J.A., 1990, A networked computer configuration for seismic monitoring of volcanic eruptions: U.S. Geological Survey Open-File report 90-422, 19 p., https://doi.org/10.3133/ofr90422.

McNutt, S.R., and Marzocchi, W., 2004, Simultaneous earthquake swarms and eruption in Alaska, fall 1996-statistical significance and inference of a large aseismic slip event, Bulletin of the Seismological Society of America, v. 94, p. 1831-1841.

Power, J.A., March, G.D., Lahr, J.C., Jolly, A.D., and Cruse, G.R., 1993, Catalog of earthquake hypocenters at Redoubt Volcano and Mount Spurr, Alaska-October 12, 1989December 31, 1990: U.S. Geological Survey Open-File Report 93-685-A, 57 p., https://doi.org/10.3133/ofr93685A. 
Richter, C.F., 1958, Elementary Seismology: San Francisco, W. H. Freeman and Company, 768 p.

Robinson, M., 1990, Xpick user manual, version 2.7: University of Alaska Fairbanks, Seismology Lab, Geophysical Institute, $93 \mathrm{p}$.

Rogers, J.A., 1993, XDETECT version 3.18 user's guide: U.S. Geological Survey Open-File Report 93-261, 18 p., https:// doi.org/10.3133/ofr93261A.
Rogers, J.A., Maslak, S., and Lahr, J.C., 1980, A seismic electronic system with automatic calibration and crystal reference: U.S. Geological Survey Open-File Report 80-324, 48 p., https://doi.org/10.3133/ofr80324.

Stein, S., and Wysession, M., 2003, An introduction to seismology, earthquakes, and earth structure: Malden, Mass., Blackwell Publishing, 498 p. 


\section{Appendix-TAR File for the Alaska Volcano Observatory Unified Earthquake Catalog-1989-2018}

The appendix consists of a compressed UNIX computer operating system tar file (tar stands for tape archive) that accompanies this report (available only online at https://oi.org/10.3133/sir20195037). The file contains all of the necessary computer files to calculate earthquake hypocenters and magnitudes using either Hypoellipse (1989 to 2012) or Hypoinverse (1989 to 2018), as well as recalculated hypocenter summary records and system response files.

The tar file has four subdirectories with the following contents:

1. Hypoi-input files needed for Hypoinverse.

2. Hypoe —input files needed for Hypoellipse.

3. Summary — phase and summary files for Hypoinverse (1989 through 2017) and Hypoellipse (1989 through January 2012).

4. Response - dataless Standard for the Exchange of Earthquake Data (SEED) volumes for pre-2002 and 2002 to 2018.

A few additional things should be noted:

- It is best to get new dataless SEED volumes from the Incorporated Research Institutions for Seismology (IRIS).

- Hypoellipse phase and summary files may have small periods of missing data.

- Hypoinverse files are likely much more complete.

- Velocity models for Hypoinverse are in the hypoi/current/models directory. 

Menlo Park Publishing Service Center, California

Manuscript approved for publication April 30, 2019

Edited by Phil A. Frederick

Layout and design by Kimber Petersen 


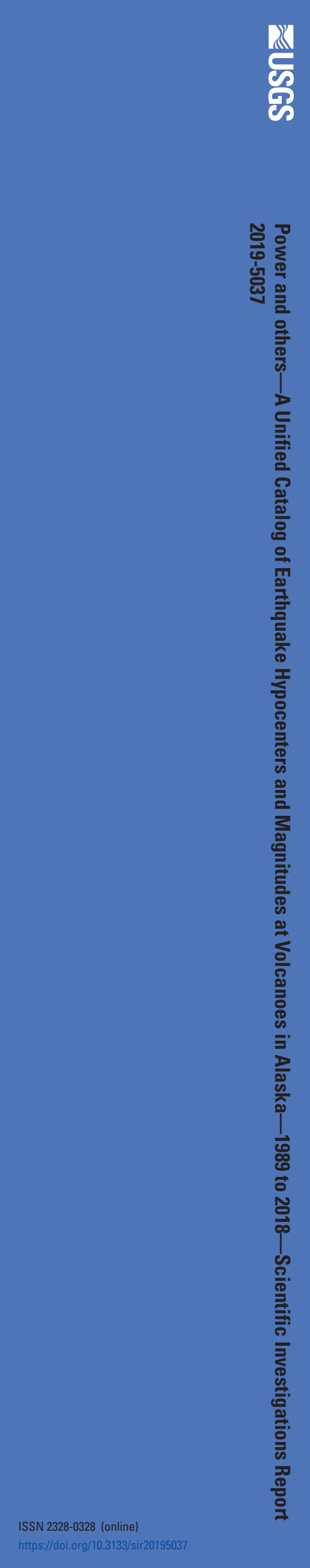

